\section{Patrimônio oral: memórias sobre o Cinema da Floresta e a Produtora de Cinema Regina}

\author{
GONÇALVES, Raruza Keara Teixeira ${ }^{1}$ \\ Universidade Federal de Juiz de Fora (Minas Gerais) \\ MUSSE, Christina Ferraz ${ }^{2}$ \\ Universidade Federal de Juiz de Fora (Minas Gerais)
}

Resumen: La transición entre los siglos XIX y XX se ha marcado por el proceso de modernización en Brasil. En el seno de las élites económicas, el capital originado en la actividade agrícola - como el café -, fué utilizado para inversión en otras áreas, incluyendo la Industria, pero también para la promoción de la Cultura. Este artículo muestra cómo, en la ciudad de Juiz de Fora (Província brasileña de Minas Gerais), un importante grupo familiar productor de café - los Assis -, fué de suma importancia para el desarrollo urbano y de diversas actividades culturales. Desde el soporte teórico de la História Oral, se coloca en evidencia la creación del Cinema da Floresta, en los años 1950, y la figura del ingeniero Júlio Álvares de Assis (un pionero en la producción de películas y registros del cotidiano). Además, se habla de la creación de la Productora de Cinema Regina, en São Paulo, en la década de 1940.

Palabras clave: Medios Audiovisuales, Cinema, Identidade, História Oral, Memoria
Resumo: A transição entre os séculos XIX e XX foi marcada pelo processo modernizador, pelo qual o Brasil passava. Entre as elites econômicas, o capital advindo da atividade agrária, como o cultivo do café, foi utilizado para investimentos em outras áreas, entre elas, a indústria, mas também contribuiu para o fomento à cultura. Dessa forma, este artigo mostra como, na cidade de Juiz de Fora, Minas Gerais, um grupo familiar, oriundo da cafeicultura, os Assis, foi de suma importância para viabilizar o desenvolvimento urbano e diversas ações culturais. A partir do suporte teórico da história oral coloca-se em evidência a criação do Cinema da Floresta, na década de 50, e a personalidade do engenheiro Júlio Álvares de Assis, pioneiro na produção de filmes e registros da vida doméstica, e na criação de uma produtora de cinema, a Produtora de Cinema Regina, em São Paulo, na década de 40 .

Palavras-chave: mídia audiovisual; cinema; identidade; história oral; memória.
1 Graduada em Comunicação Social. Ex-bolsista de Iniciação Científica. Mestranda do PPGCOM/UFJF. Integrante do projeto de pesquisa "Cidade e memória: a identidade urbana pela narrativa audiovisual".

2 Professora do PPGCOM/UFJF, mestre e doutora em Comunicação e Cultura pela UFRJ. Líder do Grupo de Pesquisa Comunicação, Identidade e Cidadania. Coordenadora do projeto de pesquisa "Cidade e memória: a identidade urbana pela narrativa audiovisual". 


\section{O resgate da história não-oficial}

No primeiro semestre de 2010, idealizamos o projeto de pesquisa: "Cidade e Memória: a identidade urbana pela narrativa audiovisual", com o objetivo, entre outros, de localizar, restaurar e classificar o acervo de produção em película, fita magnética e suportes digitais do período de 1960 a 2010, na cidade de Juiz de Fora, Minas Gerais. Estabeleciam-se assim os parâmetros para a investigação das imagens da cidade a partir do que tinha sido registrado sobre ela pela produção de amadores e de cineastas e "videomakers" profissionais. Não nos interessava mais a temática da "cidade na TV", amplamente pesquisada no projeto anterior "Televisão e imaginário urbano: as narrativas da cidade no espaço dos telejornais", que foi finalizado com a elaboração do documentário "Cidades Possíveis", em 2009, mas as maneiras de narrar a cidade que ficaram à margem dos meios massivos de divulgação de conteúdos e imagens.

No trabalho de inventariar acervos e coletar depoimentos inéditos sobre o período, acabamos por mergulhar mais fundo nessa história da cidade que escapa ao espaço dos livros, jornais e outros suportes que narram de forma objetiva a passagem do tempo. Foi durante algumas sessões de entrevistas, que deparamos com parte do material que é aqui apresentado: o Cinema da Floresta e a Produtora de Cinema Regina. Assuntos que vieram à tona, através da aplicação de técnicas utilizadas pela história oral, que conseguem revitalizar memórias e impressões que, de outra forma, estariam fadadas ao esquecimento. Para Thompson:

\begin{abstract}
Não se pode operar na vida sem essa memória; ela é a parte mais central da consciência humana ativa, e é essencialmente oral. Para nos lembrarmos dela, podemos ser auxiliados por documentos escritos, mas grande parte depende só de nossa memória oral. Sem a memória pessoal não podemos viver, não podemos ser seres humanos (THOMPSON, 2006, p.18).
\end{abstract}

Thompson não define a história oral como método ou disciplina. Ele encontra nela "abordagem ampla, é a interpretação da história e das sociedades e culturas em processo de transformação, por intermédio da escuta às pessoas e do registro das histórias de suas vidas" (id.ibid., p.20). Portanto, o autor considera a história oral como campo interdisciplinar e defende que ela "é parte dos estudos culturais em geral, pois se baseia nessa forma fundamental de interação humana, que transcende as disciplinas" (id,ibid., p. 20).

No atual estágio de nossa pesquisa, estamos realizando entrevistas, isto é, trabalhando com o registro de histórias de vida, e, ao mesmo tempo, fazendo um levantamento de memórias escritas, como documentos e cartas, e memórias visuais, que são aquelas registradas nos suportes audiovisuais (no nosso recorte, não trabalharemos com suportes como pintura ou fotografia).

$\mathrm{Na}$ sequencia de fragmentos aqui relatados, observamos a incorporação de novas vozes e percepções àquela história já sistematizada. Fontes normalmente não ouvidas nas narrativas da mídia ou dos registros oficiais revelam aspectos novos da cidade e de seus personagens, permitindo um entendimento mais amplo do que é a história narrada pela memória, isto é, pela emoção, uma "crônica do quotidiano", no dizer de Ecléa Bosi (2003, p.15).

\section{A cidade moderna e o cinema}

A transição entre os séculos XIX e XX é permeada por mudanças advindas da luta republicana e da industrialização. O Brasil como nação emergente passa por alterações relevantes a partir da segunda metade do século XIX, e tem em sua forte elite econômica agrária, interessada em expandir seus lucros, um dos elementos dinamizadores da indústria e dos investimentos culturais.

A cidade de Juiz de Fora, considerada cidade de passagem, por sua localização favorável, viverá plenamente os resultados dessas transformações sociais e econômicas. Sua forte elite, oriunda do meio rural, será responsável por um período de crescimento e desenvolvimento locais. Apesar da tradição escravocrata, a cidade não ficará estagnada. Emancipada em 1850, ela terá no capital gerado pela atividade cafeeira o meio para viabilizar o projeto modernizante das elites locais. Com uma posição geográfica favorável, a cidade faz parte de diversas rotas comerciais, contribuindo com o escoamento do café, o que a transformou em um dos principais entrepostos comerciais do produto da Zona da Mata Mineira.

É neste cenário, que ganham destaque vários grupos familiares, que investem na indústria, especialmente a têxtil, e também nas atividades culturais. São empreendedores que planejam e organizam o centro 
urbano, trazendo para ele definitivamente o modo de vida burguês.

Em 1889, é inaugurada em Juiz de Fora a primeira usina hidrelétrica da América Latina, a Usina Marmelos, empreendimento que dará origem à Companhia Mineira de Eletricidade (CME), fruto do grupo industrial Bernardo Mascarenhas, que construíra na cidade importante indústria têxtil. A empresa era responsável pelo fornecimento de energia para a iluminação de ruas e casas, assim como para a atividade industrial. Juiz de Fora substituiria os lampiões a gás pela iluminação elétrica, antes mesmo que a Velha Europa. Em 1911, a CME passa a ser controlada por um grupo de capital agrário os Assis Penido (BARROS, 2008).

Com recursos disponíveis, o município caminhava rumo ao "progresso". Neste recorte temporal que perpassa meados do século XIX e as primeiras décadas do século $\mathrm{XX}$, nota-se que a cidade tomou para si posições vanguardistas no que tange não só à economia e à indústria, mas também à cultura. A primeira exibição cinematográfica em Minas Gerais ocorre em Juiz de Fora no ano de 1897. Nesse período, a cidade era palco de vários espetáculos teatrais, tinha imponentes colégios, jornais e instituições culturais, que tinham "o papel de, além de formar os trabalhadores e quadros burocráticos, incutir na opinião pública o desejo de "civilizar-se" (CHRISTO, 1994, p.1).

De acordo com Christo (id.ibid., p.10), a singularidade de Juiz de fora não residiu apenas no fato da cidade não ter participado do ciclo minerador, mas também por um forte sentimento de anti-barroquismo, entendido o barroco como forma de vida. "Enquanto as cidades barrocas se formam e se guiam pelos sinos das igrejas, a população de Juiz de Fora teve sua vida normatizada pelos apitos das fábricas de estilo neoclássico e o bater dos tamancos de seus operários de ambos os sexos e diversas nacionalidades".

Para a elite de Juiz de Fora, civilizar-se significava muito mais estar perto do Rio de Janeiro, a capital da República e cidade até então mais importante do país, do que de Belo Horizonte, a capital do estado, que era muita distante, não só em quilômetros como em hábitos. $\mathrm{O}$ intercâmbio com o Rio de Janeiro era constante, e a influência francesa, tanto lá como cá, marcante. A elite pensante escrevia nos jornais, promovia debates e fundou, em Juiz de Fora, no ano de 1909, a Academia Mineira de Letras, que, só mais tarde, seria transferida para Belo Horizonte. Em 1922, com uma população de
118.166 habitantes, Juiz de Fora tinha seis jornais diários e era considerada a capital intelectual do estado (MUSSE, 2008).

\section{Os novos empreendedores}

A sociedade juizforana passava a se orientar por distintos valores, que representavam o ideário de vida cosmopolita e burguês. Não apenas a cidade e as relações com o espaço rural sofreram mudanças, vê-se a necessidade da criação de novos aparatos que garantam a esta elite local desenvolver novos hábitos e atividades referentes à sua realidade próspera.

Numa época em que o poder público municipal ainda não contava com uma estrutura administrativa e de arrecadação compatíveis, que pudessem vir a atender as nossas necessidades imprimidas por um padrão de vida, alterado principalmente devido ao desempenho da cafeicultura, levou que segmentos da sociedade se organizassem tanto para uma participação efetiva nas decisões, bem como, agir diretamente através de obras assistenciais, de divertimento público, etc (PASSAGLIA, s.d., p.133).

Como personagens que ilustram esta elite local elege-se, como objeto de análise, o grupo familiar e industrial dos Assis Penido, com a finalidade de dimensionar de que maneira, estes se tornaram agentes na construção da cidade de Juiz de Fora moderna.

A união entre Carolina Isabel Campos e Francisco Ribeiro de Assis (1807-1871) deixou um legado de desenvolvimento na zona rural juizforana, o que, posteriormente, pelas mãos de seus descendentes, alcançaria a cidade. $\mathrm{O}$ casal foi responsável pela construção da sede e das benfeitorias da Fazenda da Floresta $^{3}$, adquirida em 1858, por Francisco de Assis. Com a morte do mesmo, após oito anos de casamento, dona Carolina de Assis deu continuidade ao trabalho que realizava junto ao marido.

O casal teve seis filhos, contudo, com o falecimento precoce de dois destes, deram continuidade à linhagem: Maria Carolina Assis, que se casaria com João Nogueira Penido Filho; Ignacio, que se casaria com Olga

3 A Fazenda da Floresta existe até hoje. Ela deu origem aos bairros Retiro, Jardim Esperança e Floresta, na zona sudeste de Juiz de Fora. Atualmente, a fazenda pertence ao engenheiro MárioAssis Ribeiro de Oliveira.
81 
Penido Burnier, sobrinha de João Penido; Theodorico, que daria continuidade ao trabalho de sua mãe frente à Fazenda da Floresta e se casaria com Emerenciana Barbosa Álvares de Assis e, enfim, Ana Carolina de Assis.

É importante destacar que a Fazenda da Floresta sob a administração de Carolina de Assis tornou-se um modelo administrativo. Com suas lavouras de café, milho, feijão, a criação de gado, porcos e carneiros, a Fazenda da Floresta se bastava, fora apenas o sal (id. ibid., p.135). Assim, permaneceu por alguns anos, até que com a abolição da escravidão em 1888 e a crise do café, a fazenda teve que ser arrendada, fazendo com que Carolina de Assis se retirasse para a cidade, adquirindo "uma das mais modernas residências daquela época" (id. ibid., p. 135).

Mas, dois anos depois, em 1890, João Penido toma a frente dos negócios da família. E, no final da última década do século, inicia-se o ciclo áureo da Fazenda da Floresta e do direcionamento de recursos para outras áreas de investimento como a indústria. Em 1894, Theodorico Ribeiro de Assis passa a comandar os negócios do grupo familiar e sua atuação administrativa vai até 1940 .

O grupo familiar Assis Penido, como já mencionado, passa a gerir a Companhia Mineira de Eletricidade em 1911, e dessa iniciativa industrial virão outras. Eles serão os responsáveis pela Companhia de Bondes, Companhia Telefônica e a Fábrica de Tecidos São João Evangelista, fundada em 1922, na Floresta. Estes empreendimentos repercutiram no entorno da cidade, que entrava no cenário civilizatório modernista, alterando ruas, que passavam a ser iluminadas, e tinha nos palacetes de arquitetura eclética o reduto das tradições, mas também a ousadia da época:

O entrelaçamento destas duas famílias veio a constituir uma união de forças econômicas vinculadas aos setores mais dinâmicos do município, o agrário e o industrial e o do serviço de fornecimento de eletricidade, ao serem os principais acionistas da antiga Companhia Mineira de Eletricidade, mas também social e cultural...( id.ibid., p. 138).

A Fábrica de Tecidos São João Evangelista, no bairro Floresta, ilustra esta mentalidade vanguardista da família Assis, uma vez que eles implantavam no meio rural maquinário dos mais modernos utilizados na Europa. Havia um espírito de mudança e a fábrica era o espaço para que este se consolidasse. Segundo Margarida Maria Assis de Oliveira Ferraz, a relação entre o operariado e a direção era de reciprocidade, e a fábrica adotava medidas assistenciais para os seus operários:

A família por parte do meu pai, os meus ancestrais,
meus avôs, bisavôs tinham esta vontade de
melhorar a vida dos operários. A vida do meu pai
era ficar na fábrica, e a fábrica naquela época tinha
um progresso muito grande... (FERRAZ, 2010).

Nas palavras de José Paulo Netto, estas elites são a representação da identidade da cidade operáriaindustrial, que permaneceu até meados do século XX, quando uma nova vocação, a de prestação de serviços, se transformou na mais importante característica de Juiz de Fora. O pesquisador aponta também diferenças entre as elites da cidade moderna (até 1960) e da cidade contemporânea. Para ele, mesmo dentro da ordem capitalista, havia um maior comprometimento das elites, que viviam na cidade moderna, com o espaço público:

...era uma oligarquia que tinha formação cultural. (...) Que tinha atividades culturais e reunia figuras independentemente dos juízos que você possa fazer sobre suas posições, ou suas eventuais obras; era gente que valorizava a cultura (NET'TO apud MUSSE, 2008, p.138).

Dessa forma, nota-se que a família Assis realizou, a partir daquele projeto industrial, uma mudança nos meios social e cultural com a criação, entre outras ações, de um cinema em um dos galpões da fábrica. Num período em que não havia sequer menção à questão de responsabilidade social das empresas, percebe-se que a família Assis se antecipou, investindo em setores que também ainda não recebiam a devida atenção do Estado.

\section{$O$ audiovisual conquista o meio rural: um cinema na Floresta}

A posição privilegiada de Juiz de Fora frente ao contexto modernizante no qual o Brasil se inseria contribuiu para a mesma tornar-se um centro de atração de pessoas e, portanto, de novas manifestações cotidianas. Um aspecto que merece atenção é como o cinema foi um meio de comunicação que se expandiu na cidade: 
A consolidação das salas de cinema em Juiz de Fora pode ser percebida a partir de 1911. A concorrência determinou a busca das empresas por filmes de maior sucesso no mundo. (...) Sessões ao ar livre- O Cinema Sereno- passam a ser praticadas na cidade, ocorrendo uma grande presença de crianças (BARROS, 2008, p.56).

A primeira sessão cinematográfica em Minas Gerais, no ano de 1897, pode ser considerada um momento simbólico para o nascimento da relação entre a cidade e o cinema. $\mathrm{O}$ que nos anos posteriores se configuraria em uma tradição cinematográfica local. Neste cenário é importante realçar a Carriço Film, criada por João Carriço ${ }^{4}$, na década de 20 , e que irá marcar três décadas na produção de documentários e cinejornais.

Isso nos permite concluir que o conjunto de cinejornais e documentários da Carriço Film configuram um ciclo. Em nossa proposta, chamamos a esta produção ininterrupta ciclo da Carriço Film de Juiz de Fora. Preferimos não nomeá-la "ciclo juizforano", uma vez, que só a Carriço Film filmou, durante 24 anos, sob a direção de João Gonçalves Carriço (SIRIMARCO, 2005, p.140).

O desenvolvimento da exibição cinematográfica e a produção de filmes coincidem com o processo de modernização pelo qual passava Juiz de Fora. Contudo, o que é inquietante e curioso é como este hábito pode se deslocar para o meio rural, em plena década de 50, na criação, em um dos galpões da Fábrica São João Evangelista, do Cinema na Floresta.

Logo, pretende-se mostrar como se criou este cinema e qual sua importância como meio de entretenimento e de inserção coletiva no processo das novas formas de informação e entretenimento. Ainda para elucidar como o espírito de vanguarda dos Assis persistiu nas gerações futuras, coloca-se em evidência a personalidade de Júlio Álvares de Assis, filho de Theodorico Assis Filho, que, na década de quarenta, em São Paulo, terá uma produtora de filmes, a Produtora de Cinema Regina.

4 João Carriço (1886-1959) foi um dos pioneiros do cinema mineiro, produziu cinejornais e documentários durante as décadas de 30, 40 e 50. Sua empresa, Carriço Film, configurou um "ciclo de cinema" em Juiz de Fora.
Pela investigação inédita da história do Cinema da Floresta e da Produtora de Cinema Regina, buscou-se o resgate memorial, que, sob a base teórica da história oral, resultou em um acesso ao campo da subjetividade, da consulta às lembranças e memórias. Esses fios condutores contribuíram com a reprodução de um pouco destas histórias.

\section{A “projeção" do passado e a memória dos velhos}

A história oral tem, nas últimas décadas, conquistado espaço no debate teórico em torno da historiografia. Novas perspectivas como a "História vista por baixo" e a "História das mulheres" criaram um novo caminho para a pesquisa histórica, evidenciando a importância de depoimentos pessoais e trajetórias de vida como fontes documentais para a reflexão histórica (ARAÚJO; FERNANDES apud VISCARDI; DELGADO, 2007).

De modo que a história oral situa o indivíduo como ator no processo de produção da memória coletiva, como também enfatiza o uso social do passado, colaborando com um novo olhar sobre formas de vida e de cultura. Por meio da valorização das experiências vividas pelo sujeito, seja no grupo familiar, seja em comunidade, tem-se a possibilidade de uma melhor interpretação de dados. Os fatos sociais ganham uma nova análise, a qual evidencia o papel dos personagens na construção e solidificação dos mesmos.

Com base na fala, na oralidade, a pesquisa no campo das subjetividades mergulha naquilo que Michael Pollak descreveu como "memórias subterrâneas". Estas teriam a importância de expor culturas minoritárias, opostas ou esquecidas pela "memória oficial". Todavia, o encontro com o "submerso" ou "subterrâneo" pode vir acompanhado pelas sequelas do tempo, como o esquecimento e o silêncio. "Existem nas lembranças de uns e de outros zonas de sombra, silêncios, não-ditos" (POLLAK, 1989, p.9).

As memórias sobre o Cinema da Floresta e a vida de Júlio Álvares Assis e sua Produtora de Cinema Regina mostram como estas mediações entre passado e presente abarcam aspectos-chaves das experiências pessoais, familiares e sociais. Também como o recordar vem marcado por esquecimentos que se revelam em expressões como "não me lembro bem", "acho que foi

83 
nesta mesma época". Porém, o interessante é perceber que a dicotomia lembrança - esquecimento não impediu o entrelace entre histórias.

O Cinema da Floresta foi criado na década de 50, era a transformação de um galpão de máquinas da Fábrica de Tecidos São João Evangelista em uma sala de projeção. Ele funcionava nos fins de semana, sempre em horários noturnos, uma vez que se adaptava à rotina do operariado, promovendo uma prática de lazer e entretenimento:

Eu frequentava só aos sábado, mas acho que as sessões eram aos sábados e aos domingos. As sessões eram à noite, começavam às 19 h30 e iam até 21 h30. Até o rapaz que tomava conta de lá já morreu. (...) A tela ficava em um canto e tinha até as cadeirinhas. Eu adorava ir ao cinema, porque as fitas eram boas. E eles não repetiam muito. Era para os operários mesmo, tinha também um bar e as pessoas podiam se divertir (FERRAZ, 2010).

Márcio Alcântara de Assis relembra o período do cinema e de sua predileção por seriados:

Na Floresta teve um cinema, hoje virou depósito de algodão... Eu era um dos mais jovens da família e eu assisti a muitos filmes. Eu adorava ir à sala de projeção. Lembro que só tinha um projetor. Então, quando acabava um rolo, o responsável tinha que trocar e colocar outro, era uma correria.

Tinha um seriado do Fu Manchu, um personagem oriental, que fazia uma espécie de mágica. Como na época não tinha novela, todos iam para ver e queriam saber o que iria acontecer. Passava o filme, antes vinha o seriado... Lembro que todos iam, a família ficava numas cadeirinhas, que ficavam na frente. Ah! Tinha o bar que funcionava do lado da fábrica, os operários e todas que moravam por perto também se divertiam lá (ASSIS, 2010).

A partir de individualidades notam-se elementos vividos e compartilhados pelas gerações passadas, desde a série cinematográfica, a ausência da TV e das novelas, a predominância do cinema e as limitações tecnológicas do meio. A memória está intrinsecamente relacionada à organização social da vida. É a partir da memória individual, que se constrói a história oral, que serve "como espelho do individuo ou do grupo e é erigida a partir de parâmetros subjetivos..." (ARAÚJO;
FERNANDES apud VISCARDI; DELGADO, 2007, p.25).

Esta mediação entre passado e presente retoma a importância da "memória dos velhos", em que traços identitários de uma geração ganham espaço para serem revivificados, dando um suporte de sobrevivência a estes personagens por meio de suas narrativas:

Eu adorava o cinema, porque eu era menina também. E era tudo tão bem organizadinho, tinha um filme maravilhoso também, que até hoje eu queria rever. Chamava-se "Uma Rosa de Esperança", lindo, lindo, lindo, era sobre a guerra. E o filme se projetava lá, eu não perdia um quando estava de férias... (FERRAZ, 2010).

O cinema na Floresta durou até a década de 60. Após o casamento, Margarida Maria Assis de Oliveira Ferraz não se recorda do desfecho do cinema:

Meu pai (Theodorico de Assis Filho) foi para a Mineira (Companhia Mineira de Eletricidade) e deixou meu irmão e um primo cuidando da fábrica. E eu me casei, me mudei para o Rio de Janeiro. Recordo-me que, depois, complicou a situação da fábrica e eles resolveram vendê-la. (FERRAZ, 2010).

A memória oral pode mostrar visões diferentes ou opostas. Márcio Assis se recorda de um final alegre para o Cinema da Floresta com um show dos Novos Baianos, no fim dos anos 60:

Aí, um dia, um amigo nosso "pinta" nessa Fogueira (próxima ao açude do Rancho, que se localizava na Floresta) com nada mais nada menos que os Novos Baianos inteiro: Baby Consuelo, Moraes Moreira e a trupe. Estes tinham acabado de gravar "Como dois e dois". Estavam em Juiz de Fora e não tinham onde ficar, e eu, muito loucamente, os levo para ficar na Casa Grande da Floresta (exsede da fazenda). Nossa! Lembro que, na noite seguinte, o Cinema da Floresta estava lotado só de alternativos, claro, para o Show dos Novos Baianos (ASSIS, 2010).

O Cinema da Floresta foi um projeto pioneiro da nova geração dos Assis, a ele se devem histórias curiosas, retornos nostálgicos, encontros com o passado e com vivências. Mais que isso, um encontro entre pessoas e suas histórias de vida, suas memórias. 


\section{Um homem narrativa}

Júlio Álvares de Assis, filho do coronel Theodorico de Assis, antes da criação do Cinema da Floresta, na década de 50, também dará um passo pioneiro à frente da criação de uma produtora de filmes em São Paulo, na década de 40, a Produtora de Cinema Regina.

Júlio Assis nasceu em 1912, era um dos filhos caçulas do coronel Theodorico de Assis e de dona Emerenciana. Formou-se em engenharia pela Faculdade de Engenharia de Ouro Preto, concluindo os seus estudos na Escola de Engenharia de Juiz de Fora, com seu amigo Miguel Burnier.

Em 1929, Júlio conhece dona Nadyr Alcântara, natural de Fortaleza e filha do casal Alcântara Santos, que, dotados de vocação musical e artística, faziam apresentações em todo o Brasil. Após dez anos entre namoro e noivado, Júlio e Nadyr se casam em 1939. Neste período, vivem na Fazenda da Floresta, propriedade dos pais de Júlio Assis. Este trabalha na Fábrica de Tecidos São João Evangelista até 1944, quando o casal passa a viver em São Paulo.

Um período de vanguardas irá marcar a vida de Júlio Assis. De acordo com dona Nadyr, em 1946, Júlio funda a Companhia de Aviação e Linhas Aéreas Natal. Ainda segundo a mesma, Júlio Assis foi o primeiro aviador a tirar brevê em Juiz de Fora.

Júlio Assis foi considerado um homem de personalidade inventiva e alegre. Márcio Alcântara de Assis falou sobre estas características de seu pai:

Ele sempre disse para a gente que ele era um incompreendido, porque ele era um dos filhos mais novos... Ele estava ligado nas coisas do mundo, os outros mais velhos foram muito cedo encaminhados por uma educação mais rigorosa... Já ele, tia Lilina, a primeira mulher a tirar brevê em Minas Gerais, e o tio Joãozinho gostavam de tudo o que era novo. Ele sempre me disse que gostaria de ser um inventor... (ASSIS, 2010)

Margarida Maria Assis de Oliveira Ferraz reforça essas qualidades do tio:

O tio com quem tive mais contato, foi o tio Julinho, conheci até meu marido na casa dele, em um Carnaval. O tio Julinho sempre teve espírito alegre. Ele tinha uma oficina e inventava coisas. Sei que ele gostava muito de pescar e era rádioamador. Adorava tirar fotos, me lembro de uma ida a Cabo Frio, onde ele fez muitas fotos. Ele gostava de muita festa! (FERRAZ, 2010).

Nesses seis anos em São Paulo, Júlio Assis fez amigos que trabalhavam em rádios. $\mathrm{E}$ foi assim que conheceu um sócio, com o qual fundou a Produtora de Filmes Regina, em 1947. Dona Nadyr lembra que os filmes eram pequenos. A filha primogênita do casal, Regina Alcântara Assis, que teve seu nome dado à produtora, falou sobre o período:

O papai era muito empreendedor. Em São Paulo, quando ele teve a produtora de cinema, eu ainda era criança. Lembro que eu pegava os impressos e adorava, porque tinham o meu nome escrito (ASSIS, 2010).

A produtora não durou muito. E, em 1950, Júlio Assis volta a trabalhar como diretor da Fábrica de Tecidos São João Evangelista. Construiu, em 1954, o Rancho Alegre, na Floresta, onde viveu até a sua morte, em 1996. Também foi presidente do Centro Industrial de Juiz de Fora, de 1972 a 1974. Mas não parou de filmar e se interessar por cinema. Dedicou-se a filmar a família, a fazer registros domésticos de aniversários, datas comemorativas e festas.

Lá em casa tem muito $16 \mathrm{~mm}$, meu pai gostava de filmar as coisas da família, a vida dele. Lembro que ele fazia um cinema dentro de casa. Tinha um projetor de $16 \mathrm{~mm}$, então, ele fazia sessões de cinema, em que passava os aniversários, as festas e encontros (ASSIS, 2010).

Até o momento, sob a base teórica da história oral, abordaram-se personagens que narram histórias. Porém, a história de Júlio Assis e os seus registros caseiros em $16 \mathrm{~mm}$ expõem uma nova questão, em que o personagem passa a ser a própria narrativa. O que Philippe Lejeune conceituou como homens-narrativas que, por meio da prática autobiográfica, ainda que inconsciente, "se escrevem", tornam-se autores de si mesmos. "Somos sempre vários quando escrevemos, mesmo sozinhos, mesmo nossa própria vida" (LEJEUNE, 2008, p.118).

Dessa forma, ao contar sua história por meio da linguagem audiovisual, Júlio Álvares Assis projetou sua vida, seu cotidiano, seus inventos. Era uma programação

85 
familiar ver os filmes do "Tio Julinho", como reprise dos últimos fatos, encontros e festas familiares. Imagens que eram eleitas pelo olhar de Júlio, o olhar sobre sua própria vida:

$\mathrm{Na}$ verdade nunca somos causa de nossa vida, mas podemos ter a ilusão de nos tornamos seu autor, escrevendo-a, com a condição de esquecermos que somos tampouco causa da escrita quanto de nossa vida. A forma autobiográfica dá a cada um de nós a oportunidade de se crer um sujeito pleno e responsável. (...) Somos talvez, enquanto sujeitos plenos, apenas personagens de um romance sem autor. A forma autobiográfica talvez não seja o instrumento de expressão de um sujeito preexistente a ela, nem mesmo um "papel", mas antes o que determina a própria existência de "sujeitos" (LEJEUNE, 2008, p.124).

Enfim pode-se dizer que os filmes de Júlio Álvares de Assis, como uma escrita íntima, relacionamse com o processo de interiorização, permeando um trabalho de reconstrução de si mesmo, de definição de seu lugar social e de suas relações com os outros (POLLAK, 2010).

\section{Considerações finais}

$\mathrm{O}$ artigo se propôs a analisar o recorte temporal (1850-1940) e a transição do Brasil no contexto do ingresso na modernidade. Ainda apresentou como Juiz de Fora mostrou-se um espaço favorável a este período transitório e de mudanças, sendo a sua elite local um importante elemento dinamizador do mesmo.

Neste cenário, colocou-se em evidencia o grupo familiar-empresarial Assis e como este atuou à frente de ações ímpares de melhorias no espaço urbano e rural. Sob a base da história oral, trouxe à tona a existência do Cinema da Floresta e da Produtora de Cinema Regina, este último, de Júlio Álvares de Assis, estes importantes empreendimentos que resultaram na inserção local tanto no processo de exibição fílmica quanto no processo de produção cinematográfica.

O encontro com "memórias subterrâneas" foi relevante para o melhor entendimento sobre a participação das personagens no tecer dos fatos sociais. Os caminhos da tradição oral colocam o individuo não apenas como ator na história, mas também autor da sua própria história.
Portanto, voltar ao passado e buscar a partir dele elementos, que contribuam para escrever o presente, nem sempre é uma tarefa fácil. Afinal, entrelaçar histórias através de falas é realizar um exercício de atenção e às vezes de exclusão, no sentido de construir, por meio da oralidade, conexões entre os fatos narrados. Mais que isso é "reviver" um pouco essas narrativas, impressões e subjetividades e, assim, ampliar o "olhar" sobre o outro, compreender melhor a construção da própria história e de suas múltiplas identidades.

\section{Referências}

ASSIS, Márcio Alcântara de. Entrevista concedida à Raruza Keara Teixeira Gonçalves, 2010.

ASSIS, Regina Alcântara de. Entrevista concedida à Raruza Keara Teixeira Gonçalves, 2010.

BARROS, Cleyton Souza. Eletricidade em Juiz de Fora: Modernização por fios e trilhos(1889-1915). Dissertação de Mestrado. Juiz de Fora: Programa de Pós- Graduação do Curso de História da UFJF. Juiz de Fora (MG), 2008.

BOSI, Ecléa. O tempo vivo da memória: ensaios de psicologia social. São Paulo: Ateliê Editorial, 2003.

CHRISTO, Maraliz de Castro Vieira. "Europa dos pobres": a belle-époque mineira. Juiz de Fora: Ed.UFJF, 1994.

FERRAZ, Margarida Maria Assis de Oliveira. Entrevista concedida à Raruza Keara Teixeira Gonçalves, 2010.

LEJEUNE, Philipe. O pacto autobiográfico: de Roussean à Internet. Belo Horizonte: Editora UFMG, 2008.

MUSSE, Christina Ferraz. Imprensa, cultura e imaginário urbano: exercício de memória sobre os anos 60/70 em Juiz de Fora. Juiz de Fora (MG): Nankin/Funalfa, 2008.

OLIVEIRA, Marita de Assis Ribeiro de. Eles e Vocês. Juiz de Fora (MG): 1986. Mimeografado.

PASSAGLIA, Luiz Alberto do Prado. A preservação do patrimônio histórico de Juiz de Fora: medidas iniciais. Juiz de Fora (MG): Instituto de Pesquisa e Planejamento da Prefeitura de Juiz de Fora, s.d..

RESENDE, Eduardo Reis Lara. Centro Industrial de Juiz de Fora: empreendedorismo e industrialização. Juiz de Fora (MG): Ed. UFJF, 2009. 
SIRIMARCO, Martha. João Carriço: o amigo do povo. Juiz de Fora (MG): Funalfa Edições, 2005.

POLLAK, Michael. Memória, esquecimento, silêncio. Disponível em: http://virtualbib.fgv.br/ojs/index.php/ reh/article/viewArticle/2278. Acesso em out.2010.

THOMPSON, Paul. Histórias de vida como patrimônio da humanidade. In: WORCMAN, Karen; PEREIRA, Jesus Vasquez (orgs.). História falada: memória, rede e mudança social. São Paulo: SESC SP, Museu da Pessoa, Imprensa Oficial do Estado de São Paulo, 2006. p.17-43.

VISCARDI, Cláudia M. R.; DELGADO, Lucília de A. Neves. História oral: teoria, educação e sociedade. Juiz de Fora (MG): Ed. UFJF, 2007.

WORCMAN, Karen; PEREIRA, Jesus Vasquez (orgs.). História falada: memória, rede e mudança social. São Paulo: SESC SP, Museu da Pessoa, Imprensa Oficial do Estado de São Paulo, 2006.

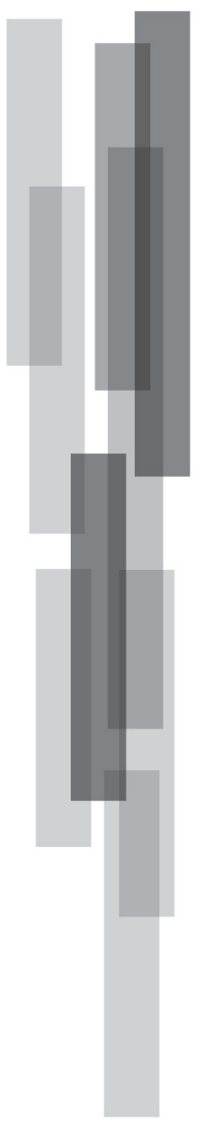

